\title{
INHIBITORY EFFECT OF ESSENTIAL OILS AGAINST Lactobacillus rhamnosus AND STARTER CULTURE IN FERMENTED MILK DURING ITS SHELF-LIFE PERIOD
}

\section{Cristiane Mengue Feniman Moritz ${ }^{1 *}$, Vera Lúcia Mores Rall ${ }^{2}$, Margarida Júri Saeki ${ }^{3}$, Ary Fernandes Júnior ${ }^{2}$}

${ }^{1}$ Departamento de Tecnologia, Universidade Estadual de Maringá, Umuarama, PR, Brasil; ${ }^{2}$ Departamento de Microbiologia e Imunologia, Instituto de Biociências, Universidade Estadual Paulista, Botucatu, SP, Brasil; ${ }^{3}$ Departamento de Química e Bioquímica, Instituto de Biociências, Universidade Estadual Paulista, Botucatu, SP, Brasil.

Submitted: December 10, 2010; Approved: June 07, 2012.

\begin{abstract}
The use of essential oils in foods has attracted great interest, due to their antagonistic action against pathogenic microorganisms. However, this action is undesirable for probiotic foods, as products containing Lactobacillus rhamnosus. The aim of the present study was to measure the sensitivity profile of $L$. rhamnosus and a yogurt starter culture in fermented milk, upon addition of increasing concentrations of cinnamon, clove and mint essential oils. Essential oils were prepared by steam distillation, and chemically characterised by gas chromatography-mass spectrometry (GC-MS) and determination of density. Survival curves were obtained from counts of L. rhamnosus and the starter culture (alone and in combination), upon addition of $0.04 \%$ essential oils. In parallel, titratable acidity was monitored over 28 experimental days. Minimum inhibitory concentration values, obtained using the microdilution method in Brain Heart Infusion medium, were $0.025,0.2$ and $0.4 \%$ for cinnamon, clove and mint essential oils, respectively. Cinnamon essential oil had the highest antimicrobial activity, especially against the starter culture, interfering with lactic acid production. Although viable cell counts of L. rhamnosus were lower following treatment with all 3 essential oils, relative to controls, these results were not statistically significant; in addition, cell counts remained greater than the minimum count of $10^{8} \mathrm{CFU} / \mathrm{mL}$ required for a product to be considered a probiotic. Thus, although use of cinnamon essential oil in yogurt makes starter culture fermentation unfeasible, it does not prevent the application of L. rhamnosus to probiotic fermented milk. Furthermore, clove and mint essential oil caused sublethal stress to L. rhamnosus.
\end{abstract}

Key words: Lactobacillus rhamnosus, starter culture, essential oils, fermented milk.

\section{INTRODUCTION}

One of the most important parameters influencing the development of probiotic foods is the viability of probiotic cells, which depends on numerous secondary elements: optimal growth and survival during food processing; storage; transit through the gastrointestinal tract; adherence to the intestinal epithelium; antimicrobial properties; and antibiotic resistance

*Corresponding Author. Mailing address: Department of Technology, Regional Campus of Umuarama, State University of Maringá, Umuarama-PR, Brazil.; Tel./Fax.: +55 044 36219317.; E-mail: crisfeniman@yahoo.com.br 
(21). In addition, probiotic microorganisms must remain viable during large-scale production and incorporation into food products without loss of functionality (16).

The main bacterial genera considered for use as probiotics are Lactobacillus and Bifidobacterium, which can be incorporated into foods alone or in combination. According to Brazilian legislation, to produce beneficial effects, probiotic bacteria must be viable, with a concentration between $10^{8}$ and $10^{9} \mathrm{CFU} / \mathrm{g}$ product, and their consumption should be associated with a balanced diet and healthy lifestyle (2). Several functional properties associated with Gram-positive lactobacillus L. rhamnosus have been reported in the literature, including: an anti-obesity effect (18), gastrointestinal tract colonisation (15, 17), enhanced immunity (22), antiinflammatory bowel disease (IBD) effects (5); and anticarcinogenic effects (13).

However, milk fermentation by one or more probiotic species requires a long incubation period, resulting in a lowquality product; thus, probiotics are generally produced in association with a yogurt starter culture. Yogurt is traditionally obtained by fermentation of a starter culture composed of Streptococcus thermophilus and Lactobacillus delbrueckii ssp. bulgaricus (22).

The viability of probiotic bacteria is mainly affected by competition with other contaminating microorganisms. Thus, it is important that undesirable cells be inactivated, without interfering with the development of beneficial bacteria (16).

The addition of essential oils (EOs) to foods has aroused great interest, because of their antagonistic action against pathogenic and spoilage microorganisms. This action, however, may affect probiotic bacteria in probiotic containing foods. Thus, the present study aimed to determine the antimicrobial activity of cinnamon, clove and mint EOs (at the maximum accepted concentration, based on a previous sensory analysis) against Lactobacillus rhamnosus and a yogurt starter culture, during the shelf-life period of fermented milk. In addition, in vitro assays were conducted to obtain the Minimal
Inhibitory Concentration (MIC).

\section{MATERIALS AND METHODS}

\section{Preparation of EOs and chemical analysis by gas} chromatography-mass spectrometry (GC-MS)

Cinnamon (Cinnamomum zeylanicum), clove (Syzygium aromaticum L.) and mint (Mentha piperita L.) EOs were extracted by steam distillation, using a distiller designed for EO production (model MA480 - Marconi), and their densities were obtained by weighing a $1 \mathrm{~mL}$ volume (10). Chemical characterisation was performed using a gas chromatograph attached to a mass spectrometer (GC-MS) (model QP5050A Shimazu), with a CBP-5 capillary column (50 m in length, 0.25 $\mathrm{mm}$ inner diameter and $0.25 \mu \mathrm{m}$ film thickness). The injector temperature was $250^{\circ} \mathrm{C}$ and the interface temperature was $250^{\circ} \mathrm{C}$; the detector was operated in electron impact (EI) mode at $70 \mathrm{eV}$ and Helium was used as the carrier gas. Gas chromatographic conditions for cinnamon EOs were as follows: an initial temperature of $60^{\circ} \mathrm{C}$ was followed by heating to $160^{\circ} \mathrm{C}$ at $3^{\circ} \mathrm{C} \cdot \mathrm{min}^{-1}$, heating to $220^{\circ} \mathrm{C}$ at $15^{\circ} \mathrm{C} \cdot \mathrm{min}^{-1}$, and maintenance at $220^{\circ} \mathrm{C}$ for $20 \mathrm{~min}$. For clove $\mathrm{EO}$, the initial temperature was $50^{\circ} \mathrm{C}$, followed by heating to $180^{\circ} \mathrm{C}$ at $3^{\circ} \mathrm{C} \cdot \mathrm{min}^{-1}$, and maintenance at $180^{\circ} \mathrm{C}$ for $40 \mathrm{~min}$. For mint $\mathrm{EO}$, the initial temperature was $70^{\circ} \mathrm{C}$, followed by heating to $240^{\circ} \mathrm{C}$ at $4^{\circ} \mathrm{C} \cdot \mathrm{min}^{-1}$, and maintenance at $240^{\circ} \mathrm{C}$ for $20 \mathrm{~min}$. EO components were identified based on the NIST (National Institute of Standards and Technology, MD, USA) mass spectrum analysis library, as well as data available in the literature (1).

\section{Minimal inhibitory concentration (MIC)}

Sensitivity assays were performed in triplicate for each EO in ELISA microplates, using the microdilution method (6). Assays were conducted in Brain Heart Infusion medium (BHIDifco) plus $0.5 \%$ Tween 80 ; and EO concentrations of 0.025 , $0.04,0.06,0.08,0.10,0.20,0.40,0.80,1.00,1.50$ and 2.00 
$(\% \mathrm{v} / \mathrm{v})$ were prepared in a final volume of $200 \mu \mathrm{L}$ medium. Positive (bacteria plus culture medium) and negative (culture medium only) control assays were also assayed, and control assays for EO sterility (medium plus oils) were performed. The bacterial inoculum was standardised in $0.85 \%$ sterile saline solution according to the $0.5 \mathrm{McF}$ arland scale, from a culture obtained after growth at $37^{\circ} \mathrm{C}$ for $48 \mathrm{~h}$, resulting in a bacterial suspension of approximately $1.5 \times 10^{8} \mathrm{CFU} / \mathrm{mL}$. For the assay, $2 \mu \mathrm{L}$ of the standardised bacterial suspension was inoculated into $200 \mu \mathrm{L}$ medium containing $0.025,0.04,0.06,0.08,0.10$, $0.20,0.40,0.80,1.00,1.50$ or $2.00(\% \mathrm{v} / \mathrm{v})$ EO (cinnamon, clove or mint), yielding an initial count of approximately $10^{5}$ $\mathrm{CFU} / \mathrm{mL}$. After incubation at $35^{\circ} \mathrm{C} / 24 \mathrm{~h}$, an assay for bacterial growth was performed by addition of a redox indicator $(0.01 \%$ resazurin); blue coloration indicated a negative result, whereas pink coloration indicated a positive result for bacterial growth. The MIC was considered to be the concentration of EO at which no bacterial growth was observed after the incubation period.

\section{Sensory analysis for yogurt containing cinnamon EO}

This analysis included 28 untrained panellists of both sexes, aged 20 to 50 years old. A 9-point Hedonic Scale test was applied, with options ranging from Like Extremely to Dislike Extremely (20). This study was approved by the Ethics Committee of São Paulo State University and was carried out according to the ethical principles established in 1964 by the Declaration of Helsinki.

Yogurt was obtained by inoculating pasteurized milk with the Thermophilic Yogurt Culture Yo-Flex ${ }^{\circledR}$ (Christian HansenBrazil), which was then incubated at $42^{\circ} \mathrm{C}$ until $0.80 \%$ lactic acid was formed, followed by homogenization with $20 \%(\mathrm{w} / \mathrm{v})$ fruit pulp prepared with banana in natura and 10\% (w/v) sugar. Treatments were established by adding cinnamon EO at concentrations of $0.01,0.02,0.04,0.06,0.08,0.1,0.2$ and $0.4 \%$ $(\mathrm{w} / \mathrm{w})$.

After $48 \mathrm{~h}$ processing, two sensory analysis sessions were performed to prevent sensory fatigue by the panelists: between 09:00 and 11:00 a.m. and between 3:00 and 5:00 p.m. During each analysis period, 4 food samples with randomly interspersed concentrations were served.

Results were subjected to analysis of variance (ANOVA) and Tukey's test, and the maximum organoleptically accepted concentration for cinnamon EO in yogurt was that which received a minimum score of 7.0, equivalent to Like Moderately.

\section{Survival curve assays for $L$. rhamnosus and starter culture}

Because yogurt is prepared with pasteurised milk, this food model was used as the milk base for the fermented milk in this study. The milk base was sterilised to ensure fermentation of only the microorganisms employed in the assays. The growth medium consisted of $200 \mathrm{~mL}$ of $12 \% \quad(\mathrm{w} / \mathrm{v})$ reconstituted skimmed milk plus $10 \%(w / v)$ sugar (9). Flasks containing growth media were autoclaved at $121^{\circ} \mathrm{C}$ for $15 \mathrm{~min}$ and cooled to $42^{\circ} \mathrm{C}$. L. rhamnosus (strain ATCC 9595) was obtained from the standard collection of microorganisms at the Oswaldo Cruz Foundation (Rio de Janeiro - Brazil). The bacterial inoculum was obtained in Trypticase Soy Broth (TSB) after incubation at $35^{\circ} \mathrm{C} / 48 \mathrm{~h}$, followed by preparation of a standardised 0.5 McFarland Scale suspension $\left(1.5 \times 10^{8} \mathrm{CFU} / \mathrm{mL}\right)$ in $0.85 \%$ sterile saline solution. Aliquots $(1$ $\mathrm{mL}$ ) from this suspension were directly added to the flasks, resulting in an initial food concentration of approximately $7.5 \times 10^{5} \mathrm{CFU} / \mathrm{mL}$.

For the yogurt starter culture, a lyophilized culture of Thermophilic Yoghurt Culture Yo-Flex® (Christian HansenBrazil) was activated at a concentration of $10 \mathrm{~g} / \mathrm{L}$ per fermentation at $42^{\circ} \mathrm{C} / 4 \mathrm{~h}$. The starter culture inoculum consisted of $1 \mathrm{~mL}$ of activated culture, for a final concentration of $0.05 \mathrm{~g} / \mathrm{L}$, as recommended by the manufacturer.

The concentration of EOs used to measure the survival curves was $0.04 \%(\mathrm{v} / \mathrm{v})$, which was previously determined as described above in a sensory analysis of cinnamon EO; 
assays (measuring L. rhamnosus counts to yield a survival curve) were conducted on cinnamon, clove and mint EOs at the same concentration, to enable comparison among treatments with the 3 different EOs.

Treatments were prepared as follows: 1) LR control (without addition of EO) for L. rhamnosus; 2) LR $+0.04 \%$ cinnamon EO; 3 ) $\mathrm{LR}+0.04 \%$ clove EO; 4) $\mathrm{LR}+0.04 \%$ mint $\mathrm{EO}$; 5) $\mathrm{SC}$ control for the starter culture; 6) $\mathrm{SC}+0.04 \%$ cinnamon $\mathrm{EO}$; 7) $\mathrm{SC}+0.04 \%$ clove $\mathrm{EO} ; 8) \mathrm{SC}+0.04 \% \mathrm{mint}$ EO; 9) LR-SC control for L. rhamnosus + starter culture; 10) LR-SC + 0.04\% cinnamon EO; 11) LR-SC + 0.04\% clove EO; and 12 ) LR-SC $+0.04 \%$ mint EO.

Viable cell count assays: After addition of inoculum into the substrates for the probiotic microorganisms and starter culture, EOs were added to the respective treatment flasks. Flasks were then stored in a water bath at $42^{\circ} \mathrm{C} / 7 \mathrm{~h}$, followed by incubation at $\pm 4^{\circ} \mathrm{C}$ in a refrigerator until the end of the experiment, for a total of 28 days.
For viable cell count assays, surfaces were sown in duplicate on Petri dishes containing Trypticase Soy Agar (TSA) medium enriched with $1 \%$ yeast extract (6) at $0,1,2,3$, 4, 5, 7, 21, 37, 55, 73, 176 (7 days), 344 (14 days), 512 (21 days) and 680 (28 days) hours after serial dilution of each treatment and respective controls. The incubation period for the bacterial count was $35^{\circ} \mathrm{C} / 48 \mathrm{~h}$.

In treatments containing both L. rhamnosus and starter culture, counts were done individually for both bacteria, because their colonies have distinct morphological features: $L$. rhamnosus colonies were round, uniform, and bright white, whereas starter culture colonies were oval-shaped, nonuniform, transparent and opaque. Both colonies had a diameter of approximately $1 \mathrm{~mm}$ each.

Thus, for treatments 9 through 12, two counts were performed for each dish, for a total of 16 reading groups for the viable cell number (Table 1).

Table 1. Description of counts and treatments for L. rhamnosus and starter culture viable cell counts in the survival curve.

\begin{tabular}{ccl}
\hline Microbial count & Treatment & \\
\hline 1 & 1 & LR control (L. rhamnosus) \\
2 & 2 & LR $+0.04 \%$ cinnamon EO \\
3 & 3 & LR $+0.04 \%$ clove EO \\
4 & 4 & LR $+0.04 \%$ mint EO \\
5 & 5 & SC control (starter culture) \\
6 & 6 & SC $+0.04 \%$ cinnamon EO \\
7 & 7 & SC $+0.04 \%$ clove EO \\
8 & 8 & SC $+0.04 \%$ mint EO \\
9 & 9 & LR + SC control (L. rhamnosus count only) \\
10 & 9 & LR + SC control (starter culture count only) \\
11 & 10 & LR + SC $+0.04 \%$ cinnamon EO (L. rhamnosus count only) \\
12 & 10 & LR + SC $+0.04 \%$ cinnamon EO (starter culture count only) \\
13 & 11 & LR + SC $+0.04 \%$ clove EO (L. rhamnosus count only) \\
14 & 11 & LR $+\mathrm{SC}+0.04 \%$ clove EO (starter culture count only) \\
15 & 12 & LR + SC $+0.04 \%$ mint EO (L. rhamnosus count only) \\
16 & 12 & LR + SC $+0.04 \%$ mint EO (starter culture count only) \\
\hline
\end{tabular}

Titratable acidity: Titratable acidity was analysed at 0,3 , 5, 7, 176 (7 days) and 680 (28 days) hours. For each treatment, $10 \mathrm{~mL}$ aliquots were aseptically removed and $100 \mathrm{~mL}$ distilled water was added. Titrations were performed with Dornic solution $(\mathrm{NaOH} N / 9)$, and the volume of $\mathrm{NaOH}$ used was expressed as Dornic degrees $\left({ }^{\circ} \mathrm{D}\right)(4)$.

Statistical analysis: Results from sensory analyses were subjected to analysis of variance (ANOVA) and Tukey's test, and the maximum organoleptically accepted concentration for cinnamon EO in yogurt was that given a minimum score equal 
to 7.0, equivalent to Like Moderately.

Friedman's test was used for the viable cell count and titratable acidity data, and medians were compared using the Dunn method.

\section{RESULTS AND DISCUSSION}

\section{Chemical characterisation of EOs by GC-MS}

The measured EO densities are as follows: $1.0049 \mathrm{~g} / \mathrm{mL}$ (cinnamon), $1.0121 \mathrm{~g} / \mathrm{mL}$ (clove), and $0.8830 \mathrm{~g} / \mathrm{mL}$ (mint). Based on GC-MS, cinnamon EO contains cinnamaldehyde as the major compound, followed by cinnamyl and cineol (these 3 components make up $89.58 \%$ of the constituents identified). For clove EO, eugenol and eugenol acetate were the major compounds identified (99.66\%); while for mint EO, menthone and pulegone were the major constituents $(76.72 \%)$.

\section{Minimal inhibitory concentration (MIC)}

According to the microdilution method, MIC is defined as the lowest concentration required to inhibit visible microbial growth. MIC values are most frequently determined by either measuring turbidity or using a resazurin redox indicator; the latter has the advantage of preventing precipitation and allowing for direct reading (7). Based on MIC readings obtained using resazurin, microbial growth was not observed under any tested concentration of cinnamon EO; thus, the MIC value for cinnamon $\mathrm{EO}$ is $\leq 0.025 \% \mathrm{v} / \mathrm{v}$. For clove and mint EOs, MIC values were found to be 0.2 and $0.4 \% \mathrm{v} / \mathrm{v}$, respectively.

MIC values for cinnamon EO were reported to be $0.05 \%$ against Staphylococcus aureus and Listeria monocytogenes, other Gram-positive bacteria (20). For clove and mint EOs, MIC values against $S$. aureus were $0.25 \%$ and $1.0 \%$, respectively (12). Goñi et al. (11) obtained MIC values of $18 \mathrm{mg} / \mathrm{L}$ against Bacillus cereus for cinnamon EO in the gas phase, $54 \mathrm{mg} / \mathrm{L}$ against L. monocytogenes and Enterococcus faecalis, and $36 \mathrm{mg} / \mathrm{L}$ against $S$. aureus; whereas for clove EO,
MIC values were $18 \mathrm{mg} / \mathrm{L}$ against Bacillus cereus and $L$. monocytogenes, 90mg/L against Enterococcus faecalis, and $27 \mathrm{mg} / \mathrm{L}$ against $S$. aureus.

\section{Sensory analysis}

The acceptance of yogurt by panellists decreased as the concentration of cinnamon EO in the food increased. There was no statistical difference at $5 \%$ from the lowest concentration to $0.04 \%$ cinnamon $\mathrm{EO}$, and the mean score of 6.28 acceptance for $0.04 \%$ cinnamon EO corresponded to Like Slightly on the Hedonic Scale; however, the median score for $0.04 \%$ cinnamon EO was 7.00 , consistent with the fact that $50 \%$ of the data corresponded to Like Moderately. Thus, $0.04 \%$ was considered to be the maximum organoleptically accepted concentration.

This concentration $(0.04 \%)$ is higher than the MIC for cinnamon EO, but less than the MIC for clove and mint EO against L. rhamnosus. Although bactericidal activity was detected in vitro at concentrations lower than $0.1 \%$ EOs (23), concentrations between 0.5 and $1.0 \%$ were demonstrated to be necessary to successfully inhibit food contamination (24).

Thus, a search for technological alternatives that favour the antimicrobial action of EOs at low concentrations in foods is required; for example by identifying possible synergistic effects between EOs, or other conservation technologies. However, it is important to ensure that the concentration of EOs used in probiotic products has no effect on beneficial bacteria.

\section{Survival curve assays for $L$. rhamnosus and the starter culture}

L. rhamnosus does not produce sufficient lactic acid for the production of yogurt or other fermented milk products, and must be combined with a yogurt starter culture (22). Based on median values from the titratable acidity data (shown in Table 2), treatments containing L. rhamnosus alone did not differ from the LR control. LR treatments containing clove and mint 
EO (treatments 3 and 4) had a slight increase compared to the

LR control. However, for LR treatments containing cinnamon
EO (treatment 2), the acidity value remained close to baseline acidity values (Fig. 1).

Table 2. Medians of L. rhamnosus and starter culture viable cell counts and titratable acidity.

\begin{tabular}{|c|c|c|c|}
\hline Treatments & Description of Microbial Counts & Log & ${ }^{\mathbf{0}} \mathbf{D}$ \\
\hline 1 & 1: Control LR (L. rhamnosus) & $8.15^{\mathrm{abc}}$ & $29.5^{\mathrm{b}}$ \\
\hline 2 & 2: $\mathrm{LR}+$ cinnamon $\mathrm{EO}$ & $7.02^{\mathrm{bc}}$ & $25^{\mathrm{b}}$ \\
\hline 3 & 3: $\mathrm{LR}+$ clove EO & $7.87^{\mathrm{abc}}$ & $31^{\mathrm{ab}}$ \\
\hline 4 & $4: \mathrm{LR}+\operatorname{mint} \mathrm{EO}$ & $7.91^{\mathrm{abc}}$ & $32^{\mathrm{ab}}$ \\
\hline 5 & 5: Control SC (starter culture) & $9.99^{\mathrm{a}}$ & $55^{\mathrm{a}}$ \\
\hline 6 & 6: $\mathrm{SC}+$ cinnamon $\mathrm{EO}$ & $4.73^{\mathrm{c}}$ & $28^{\mathrm{b}}$ \\
\hline 7 & 7: $\mathrm{SC}+$ clove $\mathrm{EO}$ & $8.45^{\mathrm{ab}}$ & $52^{\mathrm{a}}$ \\
\hline 8 & $8: \mathrm{SC}+\operatorname{mint} \mathrm{EO}$ & $8.48^{\mathrm{ab}}$ & $51^{\mathrm{a}}$ \\
\hline 9 & 9: Control LR + SC (L. rhamnosus count only) & $9.13^{\mathrm{a}}$ & $55^{\mathrm{a}}$ \\
\hline 9 & 10: Control LR + SC (starter culture count only) & $10.23^{\mathrm{a}}$ & \\
\hline 10 & 11: $\mathrm{LR}+\mathrm{SC}+$ cinnamon $\mathrm{EO}$ (L. rhamnosus count only) & $6.98^{\mathrm{bc}}$ & $26^{\mathrm{b}}$ \\
\hline 10 & 12: $\mathrm{LR}+\mathrm{SC}+$ cinnamon EO (starter culture count only) & - & \\
\hline 11 & 13: $\mathrm{LR}+\mathrm{SC}+$ clove $\mathrm{EO}$ (L. rhamnosus count only) & $7.93^{\mathrm{abc}}$ & $45^{\mathrm{a}}$ \\
\hline 11 & 14: $\mathrm{LR}+\mathrm{SC}+$ clove EO (starter culture count only) & $8.76^{\mathrm{ab}}$ & \\
\hline 12 & 15: LR $+\mathrm{SC}+\operatorname{mint} \mathrm{EO}($ L. rhamnosus count only) & $7.93^{\mathrm{abc}}$ & $49^{\mathrm{a}}$ \\
\hline 12 & 16: $\mathrm{LR}+\mathrm{SC}+$ mint EO (starter culture count only) & $8.61^{\mathrm{ab}}$ & \\
\hline
\end{tabular}

the same letters in the column indicate statistically equal medians $(\mathrm{p}<0.05)$.

(-) count lower than $10 \mathrm{CFU} / \mathrm{mL}$

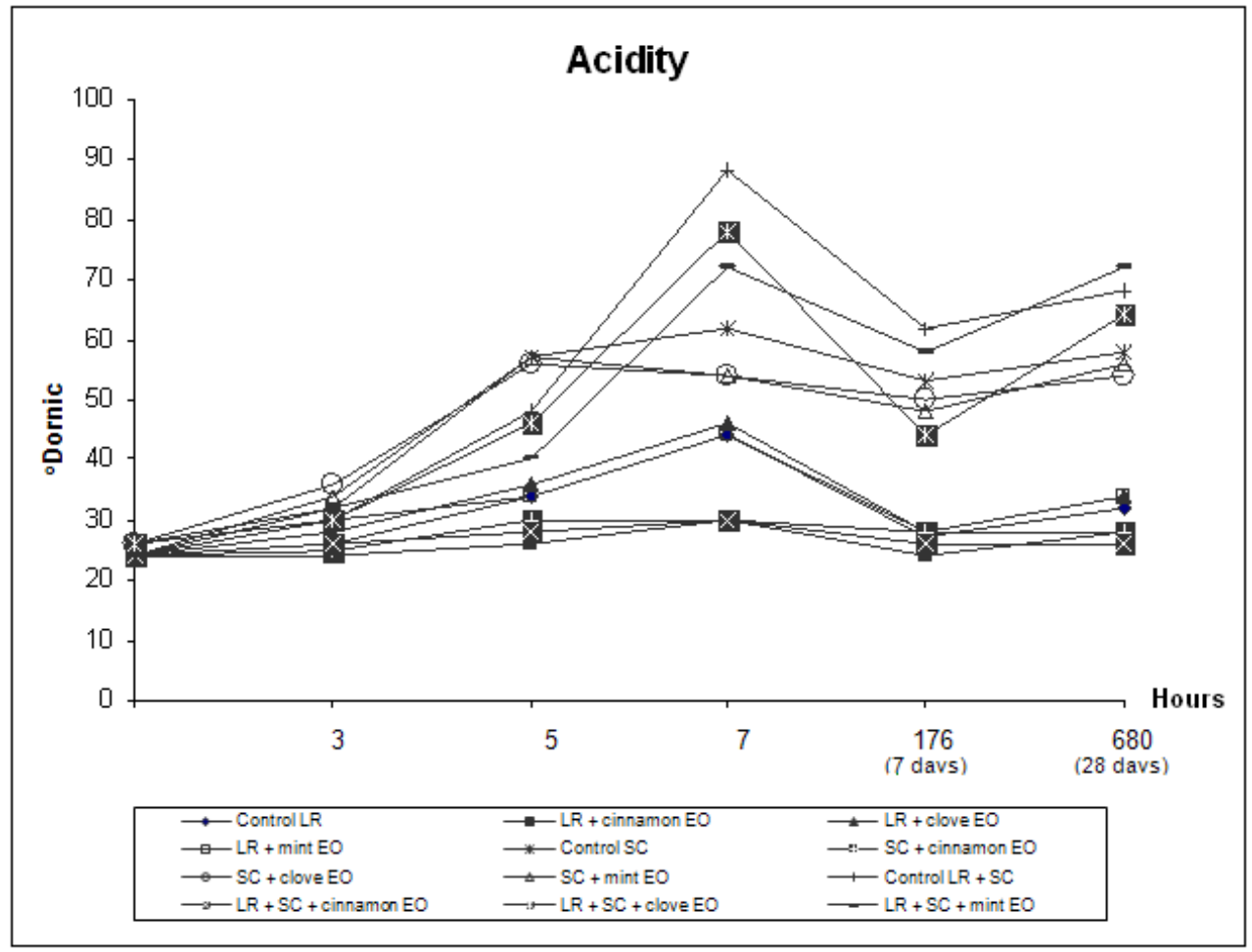

Figure 1. Determination of titrable acidity in ${ }^{\circ}$ Dornic during fermentation and storage of fermented milk containing a yogurt starter culture (SC) and L. rhamnosus (LR). Treatments contained 0.04\% EOs. 
Titratable acidity was significantly higher for treatments containing only the yogurt starter culture, including those with added clove and mint EOs. However, for treatments containing the starter culture and cinnamon EO (treatments 6 and 11), the acidity remained close to that of the LR control, which had only L. rhamnosus, indicating that cinnamon EO inactivated the starter culture.

Lactic acid production by L. rhamnosus and the yogurt starter culture can be also related to their viable cell count (Table 2). Although there was no significant decrease in the $\log$ of CFU/mL between counts for LR treatments containing EOs, and counts for LR controls, the treatment containing cinnamon EO had a more pronounced decrease of approximately $1 \mathrm{Log}$. For the starter culture, the count for the SC treatment containing cinnamon EO (count 6) displayed a marked reduction of approximately $5 \mathrm{Log}$. Counts for $\mathrm{SC}$ treatments containing clove EO (count 7) and mint EO (count 8) displayed decreases of approximately $1.5 \mathrm{Log}$; although this was not statistically significant.

For treatments containing cinnamon EO (counts 11 and 12), there was a decrease of $2.15 \mathrm{Log}$ in L. rhamnosus count (treatment 11) versus the control (treatment 9), while the median for the starter culture was lower than $10 \mathrm{CFU} / \mathrm{mL}$ (no colony growth was detected after $7 \mathrm{~h}$ ) even at a dilution of $10^{-1}$ (Fig. 2).

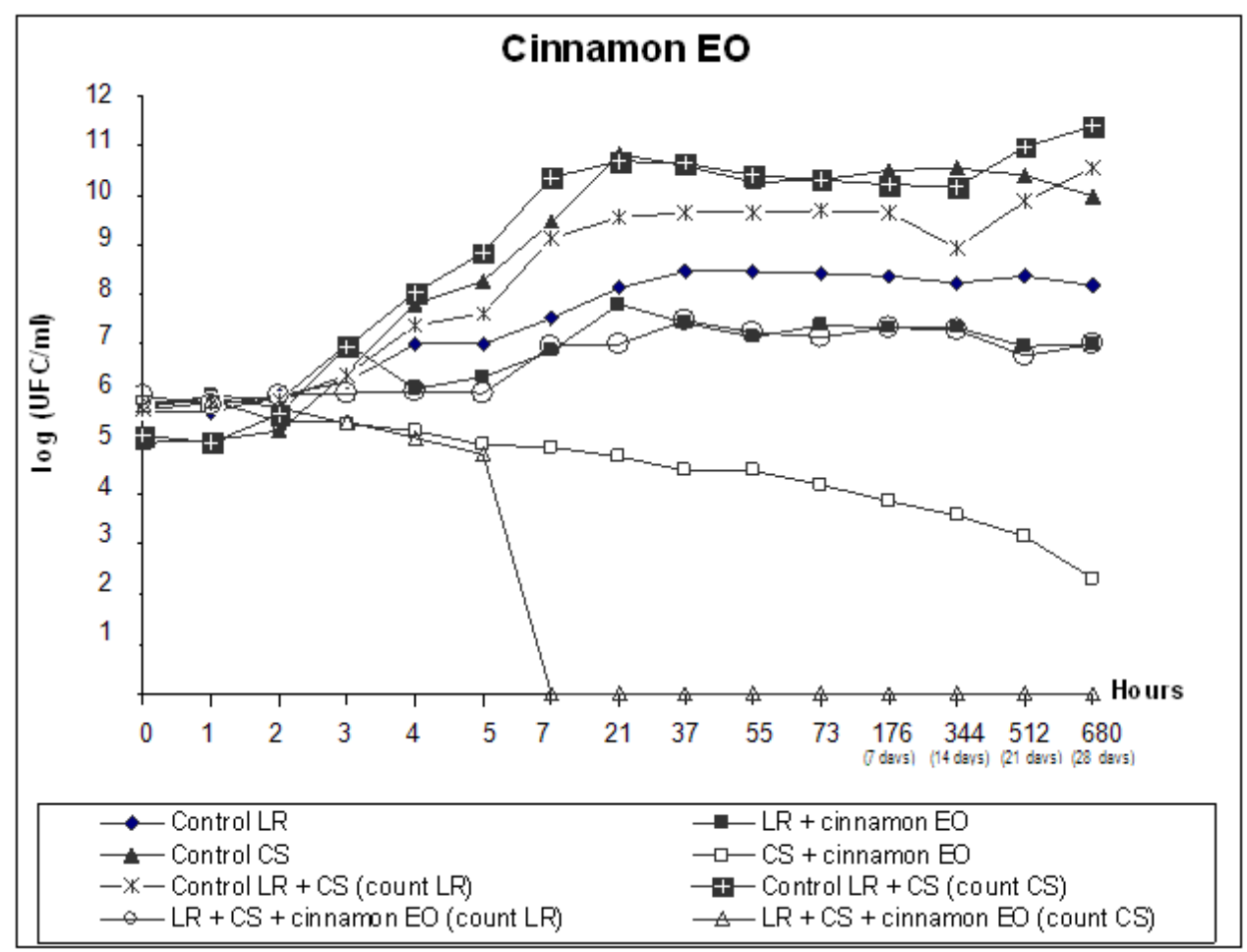

Figure 2. Viable cell counts during fermentation and storage of fermented milk with yogurt starter culture (SC) and L. rhamnosus (LR). Treatments contained $0.04 \%$ cinnamon EO.

At the end of the survival curve assay, as shown in Fig. 3 and 4, L. rhamnosus and starter culture counts for treatments containing clove and mint EOs were lower than counts 9 and 10 for their controls, although both EOs behaved similarly throughout the experiment. Median viable cell counts for the starter culture were reduced by approximately $1.5 \mathrm{Log}$, similar to counts 7 and 8 for SC treatment versus its control (count 5). On the other hand, $L$. rhamnosus was more sensitive to clove and mint EOs when 
combined with the starter culture, as evidenced by a reduction of approximately $1 \mathrm{Log}$, which is superior to the reduction of 0.28 and $0.24 \mathrm{Log}$ in counts 3 and 4 for clove and mint EOs, respectively, relative to the LR control (count 1).

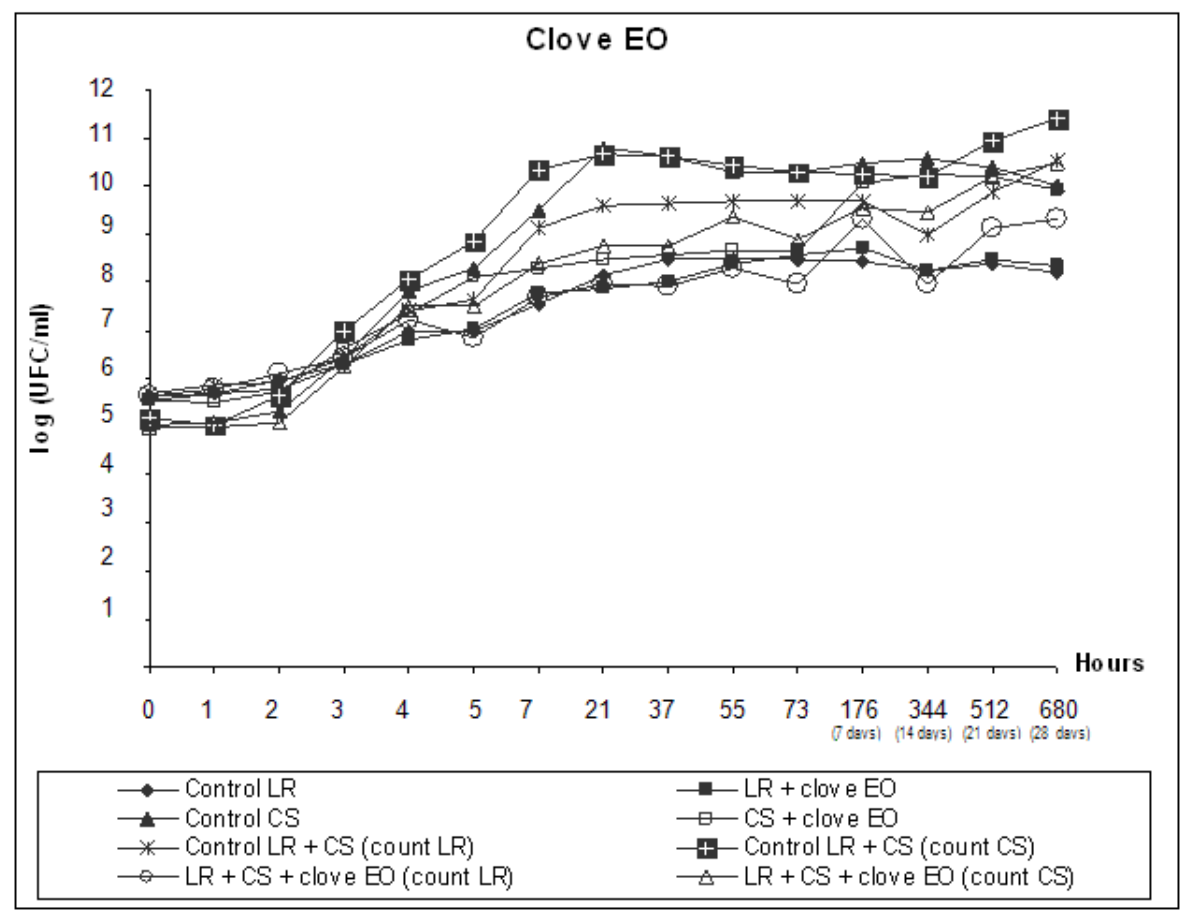

Figure 3. Viable cell counts during fermentation and storage of fermented milk with yogurt starter culture (SC) and L. rhamnosus (LR). Treatments contained $0.04 \%$ clove EO.

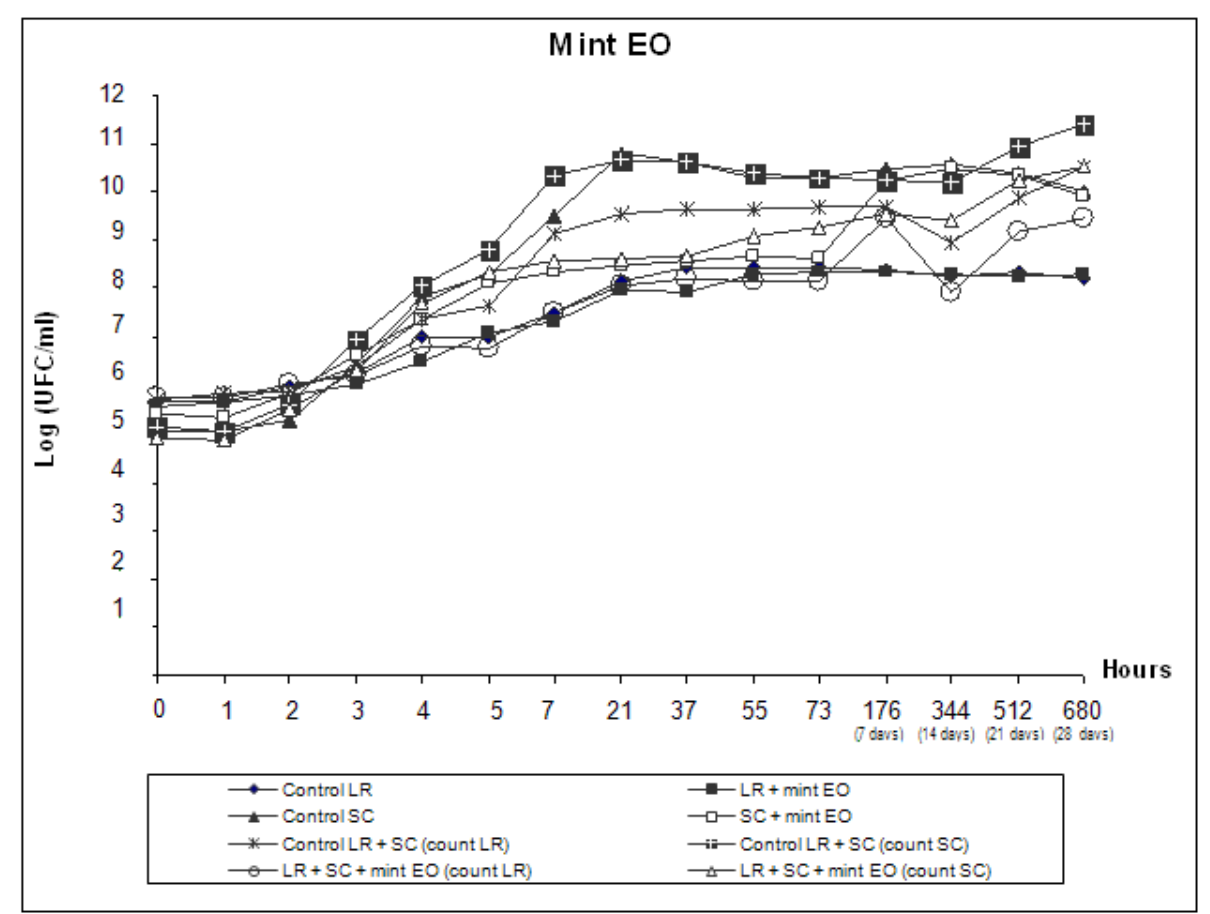

Figure 4. Viable cell counts during fermentation and storage of fermented milk with yogurt starter culture (SC) and L. rhamnosus (LR). Treatments contained $0.04 \%$ mint EO. 
With the exception of counts 6 (SC containing cinnamon EO) and 12 (starter culture count in LR+SC containing cinnamon EO), all counts for treatments containing $0.04 \%$ cinnamon, clove or mint $\mathrm{EO}$ had a minimum increase of $2 \mathrm{Log}$ at the end of 28 days of survival curve analysis. Hekmat et al. (14) reported differentiated stability behaviour for $L$. rhamnosus viable cell counts over 28 days, for yogurt supplemented with this probiotic (fermentation was done with L. delbreukii ssp. bulgaricus and S. thermophilus); after one day of storage at $4^{\circ} \mathrm{C}$, a count of $5 \times 10^{7} \mathrm{CFU} / \mathrm{mL}$ for $L$. rhamnosus was observed, which changed to $4 \times 10^{7} \mathrm{CFU} / \mathrm{mL}$ at the end of the study.

Lacroix and Yildririm (16) reported that the survival and functionality of probiotics can be improved by using fermentation technologies: such as continuous fermentation, membrane bioreactors, immobilised cells, cell encapsulation and sublethal stress during cell production; which increases the resistance of cells to environmental stress conditions during production, storage and digestion.

Thus, clove and mint EOs may have subjected the bacteria to sublethal stress, since the percentage $(0.04 \%)$ of EOs added to the treatments was less than their respective MICs $(0.2 \%$ and $0.4 \%$ for clove and mint EOs, respectively), enabling an adaptation phase during the first 3 hours, in which viable cell counts were stable, followed by a cell propagation phase in the first 24 hours, resulting in stable cell counts for the entire 28 days.

Several reports demonstrated that EOs must be used at concentrations higher than their in vitro MICs, to have antimicrobial activity in foods $(3,24)$. However, cinnamon EO displayed higher antimicrobial activity at a concentration of $0.04 \%$ than clove and mint EOs, even at a concentration close to the in vitro MIC value, explaining the significant effect observed for cinnamon $\mathrm{EO}$ on the starter culture in the food system and the resulting survival curve. However, the count of isolated L. rhamnosus treated with cinnamon EO was only reduced by $1 \mathrm{Log}$, and cell counts were above the minimum count of $10^{6} \mathrm{CFU} / \mathrm{mL}$, which is required for a product to be considered to be a probiotic. Thus, addition of cinnamon EO to fermented milk makes starter culture fermentation unfeasible, but does not prevent the use of L. rhamnosus in probiotic fermented milk.

\section{CONCLUSIONS}

The maximum organoleptically accepted concentration of EOs in yogurt in this study was lower than MIC values obtained for clove and mint EOs. Thus, only a sublethal effect was observed for these EOs on L. rhamnosus and the starter culture; and their use does not impair the fermentation process during product preparation, indicating the resistance of these microorganisms to clove and mint EOs. However, the in vitro MIC for cinnamon EO was less than the tested concentration, and addition of cinnamon EO had a significant effect on the starter culture count and leading to lower lactic acid production. However, similar to results observed for clove and mint EOs, L. rhamnosus was not significantly affected by cinnamon EO.

\section{ACKNOWLEDGEMENTS}

The authors thank the Christian Hansen-Brazil for their support through the donation of lactic culture.

\section{REFERENCES}

1. Adams, R.P. (1989). Identification of essential oils by ion trap mass spectroscopy. Academic Press, INC., San Diego, California.

2. Agência Nacional de Vigilância Sanitária (Brazil). Alimentos com Alegações de Propriedades Funcionais e ou de Saúde, Novos Alimentos/Ingredientes, Substâncias Bioativas e Probióticos VIII - Lista dos Novos Alimentos aprovados. 2008. Available on: $<$ http://www.anvisa.gov.br/alimentos/comissoes/novos_alimentos.htm>. Access on: Jan. 14, 2011.

3. Burt, S. (2004). Essential oils: their antibacterial properties and potential applications in foods - a review. Int. J. Food Microb. 94 (3), 223-253.

4. Case, R.A.; Bradley Jr., R.L.; Williams, R.R. (1992). Chemical and physical methods. In: American Public Health Association. Standard 
5. methods for the examination of dairy products. 15. ed. New York, $327-$ 404.

6. Chiu, Y.-H.; Hsieh, Y.-J.; Liao, K.-W.; Peng, K.-C. (2010). Preferential promotion of apoptosis of monocytes by Lactobacillus casei rhamnosus soluble factors. Clin. Nutrit., 29 (1), 131-140.

7. Clinical and Laboratory Standards Institute / National Comitee for Clinical Laboratory Standards (CSLI/NCCLS). (2005). Performance standards for antimicrobial susceptibility testing. Fifteenth information supplement. CLSI/NCCLS document M 100-S15. Wayne, PA.

8. Cos, P.; Vlietinck, A.J.; Berghe, D.V.; Maes, L. (2006). Anti-infective potential of natural products: how to develop a stronger in vitro 'proofof-concept'. J. Ethnopharmacol. 106 (3), 290-302.

9. Downes, F.P. (2001). Compendium of methods for the microbiological examination of foods, $2^{\text {nd }}$ edition. Washington, DC: American Public Health Association.

10. Ferreira, C.L.L.F. (2001). Produtos lácteos fermentados - aspectos bioquímicos e tecnológicos. Editora UFV, Viçosa, MG.

11. Fonseca, P.; Librand, A.P.L. (2008). Evaluation of physico-chemical and phytochemical characteristics of different tinctures of barbatimão (Stryphnodendron barbatiman). Braz. J. Pharm. Sci. 44 (2), 271-277.

12. Goñi, P.; López, P.; Sánchez, C.; Gómez-Luz, R.; Becerril, R.; Nerín, C. (2009). Antimicrobial activity in the vapour phase of a combination of cinnamon and clove essential oils. Food Chem. 116 (4), 982-989.

13. Hammer, K.A.; Carson, C.F.; Riley, T.V. (1999). Antimicrobial activity of essential oils and other plant extracts. J. App. Microb. 86 (6), 985-990.

14. Hatakka, K.; Holma, R.; El-Nezami, H.; Suomalainen, T.; Kuisma, M.; Saxelin, M.; Poussa, T.; Mykkänen, H.; Korpela, R. (2008). The influence of Lactobacillus rhamnosus LC705 together with Propionibacterium freudenreichii ssp. shermanii JS on potentially carcinogenic bacterial activity in human colon. Int. J. Food Microb., 128 (2), 406-410.

15. Hekmat, S.; Soltani, H.; Reid, G. (2009). Growth and survival of Lactobacillus reuteri RC-14 and Lactobacillus rahmnosus GR-1 in yogurt for use as a functional food. Inn. Food Sci. Emerg. Techn. 10 (2),
293-296.

16. Henryk, S.; Chmielarczyk, A.; Strus, M.; Pejcz, J.; Jawien, M.; Kochan, P.; Heczko, P.B. (2006). Colonisation of the gastrointestinal tract by probiotic L. rhamnosus strains in acute diarrhoea in children. Dig. Liver Dis., 38 (Suppl. 2), S274-S276.

17. Lacroix, C.; Yildirim, S. (2007). Fermentation technologies for the production of probiotics with high viability and functionality. Curr. Opin. Biotechn. 18 (2), 176-183, 2007.

18. Lam, E.K.Y.; Yu, L.; Wong, H.P.S.; Wu, W.K.K.; Shin, V.Y.; Tai, E.K.K.; So, W.H.L.; Woo, P.C.Y.; Cho, C.H. (2007). Probiotic Lactobacillus rhamnosus GG enhances gastric ulcer healing in rats. Eur. J. Pharm., 565 (3), 171-179.

19. Lee, H.-Y.; Park, J.-H.; Seok, S.-H.; Baek, M.-W.; Kim, D.-J.; Lee, K.E.; Paek, K.-S.; Lee, Y.; Park, J.-H. (2006). Human originated bacteria, Lactobacillus rhamnosus PL60, produce conjucated linoleic acid and show anti-obesity effects in diet-induced obese mice. Bioch. Bioph. Acta, 1761 (7), 736-744.

20. Oussalah, M.; Caillet, S.; Saucier, L.; Lacroix, M. (2007). Inhibitory effects of selected plant essencial oils on the growth of four pathogenic bacteria: E. coli O157:H7, Salmonella Typhimurium, Staphylococcus aureus and Listeria monocytogenes. Food Control. 18 (5), 414-420.

21. Poste, L.M.; Mackie, D.A.; Butler, G.; Larmond, E. (1991). Laboratory methods for sensory analysis of food. Canada Communication Group, Ottawa, Canada.

22. Ranadheera, R.D.C.S.; Baines, S.K.; Adams, M.C. (2010). Importance of food in probiotic efficacy. Food Res. Int. 43 (1), 1-7.

23. Shah, N.P. (2007). Functional cultures and health benefits. Int. Dairy J. 17 (11), 1262-1277, 2007.

24. Smith-Palmer, A.; Stewart, J.; Fyfe, L. (1998). Antimicrobial properties of plant essential oils and essences against five important food-borne pathogens. Lett. App. Microb. 26 (2), 118-122.

25. Smith-Palmer, A.; Stewart, J.; Fyfe, L. (2001). The potential application of plant essential oils as natural food preservatives in soft cheese. Food Microb. 18 (4), 463-470. 